\title{
Details and acceptability of a nutrition intervention programme designed to improve the contents of children's packed lunches
}

\author{
Christine L Cleghorn*, Charlotte EL Evans, Meaghan S Kitchen and Janet E Cade \\ Nutritional Epidemiology Group, Division of Epidemiology and Biostatistics, University of Leeds, Room 8.49 \\ Worsley Building, Leeds LS2 9JT, UK
}

Submitted 22 August 2008: Accepted 4 August 2009: First published online 22 September 2009

\begin{abstract}
Objective: To describe the 'Smart Lunch Box' intervention and provide details on feedback from the participants on the acceptability and usability of the intervention materials.

Design: A cluster randomised controlled trial, randomised by school. English schools were stratified on percentage free-school-meals eligibility and attainment at Key Stage 2. A 'Smart Lunch Box' with supporting materials and activities on healthy eating was delivered to parents and children via schools in the intervention group. Feedback forms containing information on a total of fifteen intervention items were filled out by the parents and/or children participating in the intervention and were collected after each of the three phases of the intervention.

Setting: Eighty-nine primary schools in England, Scotland, Wales and Northern Ireland, randomly selected; forty-four schools in the intervention arm.

Subjects: A total of 1294 children, aged 9-10 years, took part in the trial. Of the 604 children in the intervention arm, 343 provided feedback after at least one of the three phases.

Results: A median of twelve items out of a total of fifteen were used by responders. The two intervention items most likely to be used were the individual food boxes and the cooler bags. Whether a participant liked an item significantly affected whether they used it for all items except the cooler bag, fruity face and individual food boxes.

Conclusions: Practical intervention items aimed at parents are likely to be used in the longer term and therefore may be appropriate for use in an intervention strategy to improve packed lunches.
\end{abstract}

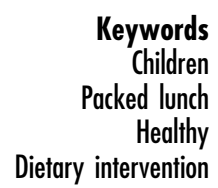

The rate of childhood obesity is currently rising in the UK. The proportion of boys and girls, aged 2-15 years, who are obese increased between 1995 and 2005 , from $10 \cdot 9 \%$ to $18 \cdot 0 \%$ in boys, and from $12 \cdot 0 \%$ to $18 \cdot 1 \%$ in girls ${ }^{(1)}$. It is likely that there are many reasons for this increase, with children's diets playing a major role. Due to this strong association between diet in childhood and obesity ${ }^{(2)}$ and later risk of chronic disease ${ }^{(2-5)}$, implementing strategies to improve children's diets have become an important focus for the UK government ${ }^{(6)}$.

Foods children consume at school have recently come into the spotlight, and new government standards on the nutritional content of school meals are being implemented between 2006 and $2009^{(7)}$. Currently, there are no such standards for foods brought into school by children but a new governmental strategy will ask all schools to develop healthy lunch box policies, so that those not taking a school meal also eat a healthy lunch ${ }^{(6)}$.
On average, around half of school pupils in the UK take a packed lunch from home ${ }^{(8)}$, which equates to a total of 840 million lunches each year ${ }^{(9)}$. A survey looking at primary-school children's lunch boxes, conducted in 2004 , found that only $52 \%$ of the lunch boxes contained a serving of fruit or vegetables while $69 \%$ included a packet of crisps and $58 \%$ included a chocolate bar or biscuits ${ }^{(10)}$. The baseline results of this intervention study ${ }^{(11)}$ revealed that only $1 \%$ of lunches met all the government standards required for packed lunches provided by schools. In all, $54 \%$ of children were provided with fruit, $19 \%$ with vegetables and $82 \%$ with snacks (savoury snacks or confectionery) in their lunch box. There is good evidence that packed lunches provide more sugar, saturated fat and sodium than school meals, although results are contradictory for total fat content ${ }^{(12-14)}$. Research has also shown that packed lunches contain fewer vegetables or salad ${ }^{(12,14)}$ but more fruit than school meals ${ }^{(12)}$. 
A search of the literature reveals a number of interventions worldwide aimed at improving the quality of children's diets with varying degrees of success, but only one small study, published as an abstract only, aiming to improve packed lunches ${ }^{(15)}$. Many of the interventions are school-based, employing methods such as targeting the curriculum, modifying school meals and teacher training. The majority of these interventions have shown some positive results ${ }^{(16-28)}$.

There are fewer intervention studies targeting parents and children at home, but parent-focused interventions may have a positive effect on children's diets through using parent/child workbooks and activities ${ }^{(29,30)}$ and educational sessions with a clinical dietitian ${ }^{(31)}$. These results suggest that family-based interventions can be effective in changing children's diets.

Acceptable and effective methods to improve the quality of food that children bring to school for lunch are necessary and there are lessons that can be learnt from other healthyeating and obesity-prevention trials in children. The literature suggests that parental involvement is an important aspect of a successful intervention, as is having engaging and interactive intervention items. In many of the earlier trials, the success has been limited. It is therefore important to explore the barriers to healthy packed lunches and tailor intervention items to overcome these barriers.

The present paper aims to describe a nutrition intervention programme that offers an innovative approach to the problem of improving the content of school lunch boxes and to describe the intervention items' acceptability to parents and children. The intervention items presented here may help to inform future interventions and policy initiatives designed to help families provide nutritious and healthy packed lunches.

\section{Methods}

\section{Development of the intervention}

The intervention was part of a randomised controlled trial carried out in a nationally representative sample of primaryschool children in Year 4 (age 8-9 years) at baseline in England, Wales, Scotland and Northern Ireland, taking a packed lunch to school. The trial was carried out in eightynine schools with a total of 1294 children. Baseline data was collected by thirteen National Foundation for Educational Research (NFER) administrators in June 2006. Intervention items were sent out to the intervention group in three phases, once in each academic term: November 2006, February 2007 and April 2007. An existing healthy-eating leaflet aimed at primary-school children was sent to children in the control group in December 2006. The NFER administrators returned to the school in June 2007 to collect data after the completion of the intervention programme.

The design of the intervention materials was based on information provided as a result of an ethnographic study conducted by Naked Eye and advice from packaging design companies (Faraday Packaging and Design Futures). The ethnography was conducted in eight families equally divided between north and south England with a mixture of living situations (two-parent households where both parents work, two-parent households where one parent works and single-parent households), ethnicities (half of AfroCaribbean, Indian or Pakistani origin, half British white) and incomes (half with an annual family income below $£ 16000$ in the north and 18000 in the south, half above this cut-off). The six main barriers to providing an adequate packed lunch that were identified by Naked Eye were peer-group pressure, poor understanding of health issues, time constraints on lunch preparation, lack of ideas when shopping for foods, poor sources of nutritional information and the less-popular presentation of healthy foods as compared to packed foods.

The developmental research identified that it was important to support parents to prepare and children to consume healthier lunches in three ways:

1. Support at the point of food shopping;

2. Support during lunch box preparation at home;

3. Support at the point of consumption at school.

Parents of the children in the intervention who were responsible for preparing the packed lunch were provided with a 'Smart Lunch Box' and supplementary materials to aid shopping for the lunch box and lunch box preparation. Advice on the content of packed lunches was based on the 'Eat Well Plate ${ }^{,(28)}$ and the government standards for packed lunches provided by schools. The materials for children were designed to give support at the point of consumption by associating eating healthy food with fun and enjoyment. The materials were also designed to encourage children to ask for healthy foods through non-food-based rewards. Details of the intervention items for parents and children can be found in Tables 1 and 2. In addition to these items, a 'Smart Lunch Box' logo was designed (see Fig. 1), which reinforced the four target food groups (fruit, vegetables, dairy and a sandwich or alternative) and was intended to act as a memory prompt.

A 'lunch box coordinator' at each school was provided with a manual, which provided detailed guidance on how to use the project materials, how to hand over the materials to parents and children, and how to access nutritionists from the University of Leeds to answer any questions or help with difficulties. The coordinator distributed the materials to all parents of children in Year 5, in the intervention arm of the trial. For phase one, the coordinators were asked to informally demonstrate the use of the lunch box materials to parents and children and to prepare lunch box foods, such as fruit and vegetables. The second and third phase items were given to children to take home to their parents without further demonstration by a teacher and included an instruction leaflet for parents on how to use each item. 
Table 1 Intervention items aimed at parents

\section{Phase one}

Cooler bag: Cooler bag with space for the two plastic boxes, a drink bottle, dairy food and the fun activities for children.

Individual food boxes: Two watertight plastic boxes. One big enough to have a sandwich or other starch-based food and a separate section for vegetables. The other smaller box was intended to keep chopped fruit fresh. Both boxes were marked with the smart lunch logo and which section was for which type of food.

Week-one menus: A week of packed lunch menus was designed to meet the guidelines for energy, fat, sugar and salt and contained a sandwich (or alternative) with protein, vegetables, fruit and dairy food. This was given out with a ready-made shopping list of the foods included in the suggested week of lunches.

Blank shopping lists: An A6 pad with a magnetic strip on the back to fasten to the fridge. Designed to enable parents to go shopping with a reminder of the four food groups for a healthy lunch box with space on the back to write down the remainder of the family's weekly shopping.

Wall chart with lunch box ideas: Folded out to give an A4 sized chart with four separate lists of ideas for the four food groups for lunch boxes, namely, sandwiches (or alternative), fruit, vegetables and dairy. All the most common foods were included so that parents and children would see familiar foods.

\section{Phase two}

Magnetic memo-board: A magnetic chart, including an erasable pen, with the days of the week down the side and the four food groups along the top. The contents of the packed lunch for the week could be decided and recorded in advance. This could also be used as a basis for a shopping list.

Help leaflet: Parents were given an easy-to-read leaflet with ideas on what to do to overcome some of the common problems parents face when trying to get their children to eat the healthy lunch they have prepared.

Wraps and pita recipes: Basic recipes on how to make a wrap and a pita recipe.

Week-two menus: A new week of menus with a ready made shopping list.

\section{Phase three}

Cloth shopping bag: A reusable cloth bag to take food shopping was designed with the logo and useful ideas for packed lunches by food type printed on one side.

Week-three menus: A new week of menus with a ready-made shopping list. This contained the most common lunch box foods to encourage parents and children who had yet to make changes to their packed lunch.

Recipe book review: For parents who had made changes and were looking for inspiration, reviews of four of the best books on lunch box foods were provided together with a recipe from each of the books.

Table 2 Intervention items aimed at children

\section{Phase one}

Fruity face: A coloured inflatable container that protects fruit and could be clipped on to a strap or placed in the cooler bag.

Sticker collection card and stickers: Had space for three weeks of stickers to be taken in the packed lunch.

A puzzle card with sticky puzzle pieces: A twenty-piece puzzle was designed for one week of healthy lunches to be taken in the packed lunch. The child gets a piece of puzzle for each of the four items of a healthy lunch s/he takes.

Membership to the Artie Beatie Club: The children were given a free membership form and a stamped addressed envelope for the British Heart Foundation children's club. If they joined, they were sent games and fun activities that increase their familiarity with different types of fruit and vegetables.

\section{Phase two}

Magnetic lunch box: Forty magnetic pieces of food from the four food groups that could be placed on the picture of an empty lunch box. This could be used by the child to indicate what they want for lunch and could also be used to encourage the child to increase consumption of healthy foods by setting a non-food-based reward.

Jokes and facts: Printed on perforated coloured card, to be included in the lunch box so that at lunch time the child had a joke or fact to tell their friends that was relevant to the fruit or vegetable in their lunch.

\section{Phase three}

Water bottle: A bottle that fitted snugly in the lunch bag was provided to encourage children to take water to school.

Top grub game: A top trump style game that encouraged children to think about the nutrients in food.

Lunch-munch chart: A list of common healthy foods to have in a packed lunch and a choice of three views - 'I like it', 'its ok' and 'I don't like it', designed to encourage the consumption of new healthy foods.

Website: Where parents and children could get information on the materials and access a range of enjoyable activities. http://www.smartlunchbox.co.uk

\section{Feedback forms}

A feedback form, asking whether the participants liked the individual intervention items, was sent out with the first phase of the intervention. Parents were asked to circle one of three options: 'yes', 'no', 'don't know'. For the second and third phases, a feedback form included intervention items with tick boxes for the following options: 'love it', 'like it', 'don't like it', 'hate it', 'don't know', as well as options for 'I have used it' or 'I haven't used it'. On the back of these forms there were questions about the intervention items from the phase before the current phase, asking if they 'have used', 'never used' or 'still use' the individual items. There were also extra questions about whether they had visited the website, used the recipes, bought a book from the book review handout or joined the Artie Beatie club. Schools collected and returned feedback forms using a pre-paid envelope. 


\section{Analysis of the data}

Analysis of the data was carried out using MLwiN software, which takes into account the multilevel structure of the data. Logistic models were built, investigating, first, the factors associated with percentage of children who had used each item and, second, the factors associated with percentage of children who had liked each item. OR were calculated to test the effect of liking of an item, gender and percentage free-school-meals eligibility (\%FSME) on the usage of an item and the effect of gender and \%FSME on whether an item was liked. \%FSME was used as an indicator of deprivation and was based on the school rather than the individual child. This indicator was split at the median of $16 \%$. Differences between the schools that returned feedback forms and those that did not, were tested using the MannWhitney test. Results are presented as percentages of responding participants and OR of covariates.

\section{Results}

\section{School response rates}

Forty-four schools were randomised to the intervention arm; two schools dropped out before receiving the intervention due to change in school head teacher and forty-two schools participated in the intervention. Seven schools did not send back feedback forms for any phase. In all, 343 (57\%) intervention children provided feedback after at least one of the three phases. A total of $37 \%$ of the children ( $n$ 223) in the intervention sent back feedback forms after phase one. These came from twenty-eight schools. The response rates for phase two and three were $38 \%$ ( $n$ 227) and 35\% ( $n$ 213) from twenty-nine and twenty-seven schools, respectively. The response rates

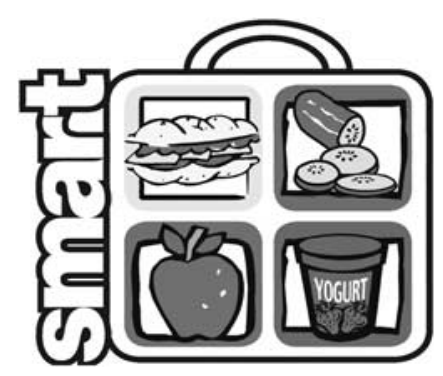

Fig. 1 Smart lunch box logo within the responding schools were $78 \%, 78 \%$ and $74 \%$ for phase one, two and three, respectively. The profile of \%FSME and Key Stage 2 results for responders and non-responders was comparable (Table 3).

\section{Use of intervention items}

Of the fifteen intervention items investigated, a median of twelve items were used by children responding to the feedback forms. Seven out of the fifteen items were deemed to be paper-based. These consisted of the jokes and facts, help leaflet, wall chart, week-one menus, blank shopping lists, sticker collection card and lunch-munch chart. A median of five of the seven paper items were used. Eight of the fifteen items were deemed to be nonpaper-based: the cooler bag, plastic boxes, fruity face, magnetic lunch box, magnetic memo-board, water bottle, cloth shopping bag and top grub game. A median of six out of the eight items were used. In all, $74.3 \%$ of responders used more than half of the paper intervention items and $98.8 \%$ used more than half of the non-paper items.

Over $70 \%$ of children used the following items: individual food boxes, cooler bags, fruity face, magnetic lunch box, sticker collection card, magnetic memo-boards and blank shopping lists (Figs 2 and 3). The individual food boxes and the cooler bags were significantly more likely to be used than all of the other intervention items (Table 4), and over $95 \%$ of children were still using these items at the following phase. Details of the percentage of parents and children using the intervention items are presented in Figs 2 and 3.

\section{Liking of intervention items}

The majority of children $(>80 \%)$ reported liking eleven out of the fifteen assessed items with 93.2\%, 89.7\% and $88.3 \%$ of children reporting liking the individual food boxes, the fruity face and the top grub game, respectively. The least popular items, the lunch-munch chart and cloth shopping bag, were still reported to be liked by $64 \cdot 3 \%$ and $67.9 \%$ of participants, respectively.

\section{Factors affecting usage and liking of intervention items}

Whether a participant liked an item significantly affected whether they used it for all items except the cooler bag, fruity face and individual food boxes. All participants

Table 3 Characteristics of schools responding and not responding to the feedback questionnaires

\begin{tabular}{lllcc}
\hline Phase & Schools & $n$ & Median \% with free school meals & Median Key Stage 2 attainment* \\
\hline 1 & Responding & 28 & 17 & 3 \\
& Non-responding & 14 & 11 & $4 \dagger$ \\
2 & Responding & 29 & 11 & 3 \\
& Non-responding & 13 & 17 & 3 \\
3 & Responding & 27 & 9 & 3 \\
& Non-responding & 15 & 19 & 3
\end{tabular}

*Data only available from English schools ( $n$ 37).

tSignificantly different from responding schools $(P=0.02)$. 


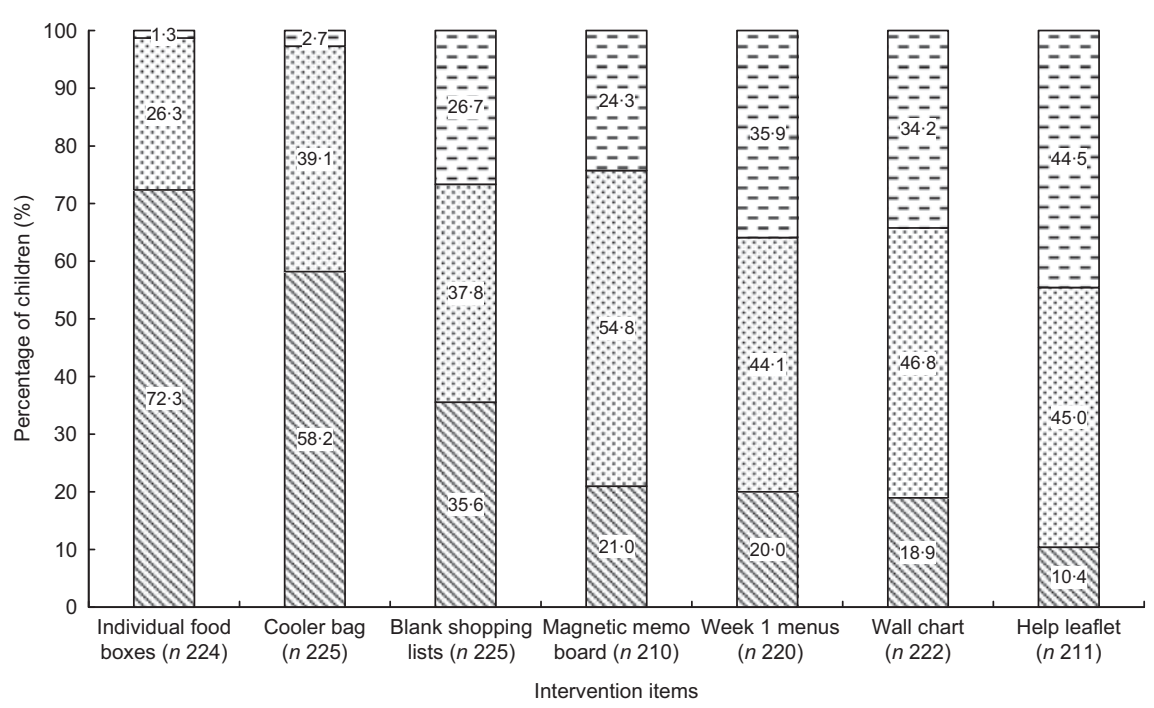

Fig. 2 Intervention items for parents. Percentage never using, using and still using intervention items at next phase (--, never used; \&, have used; $\mathbb{N}$, still using)

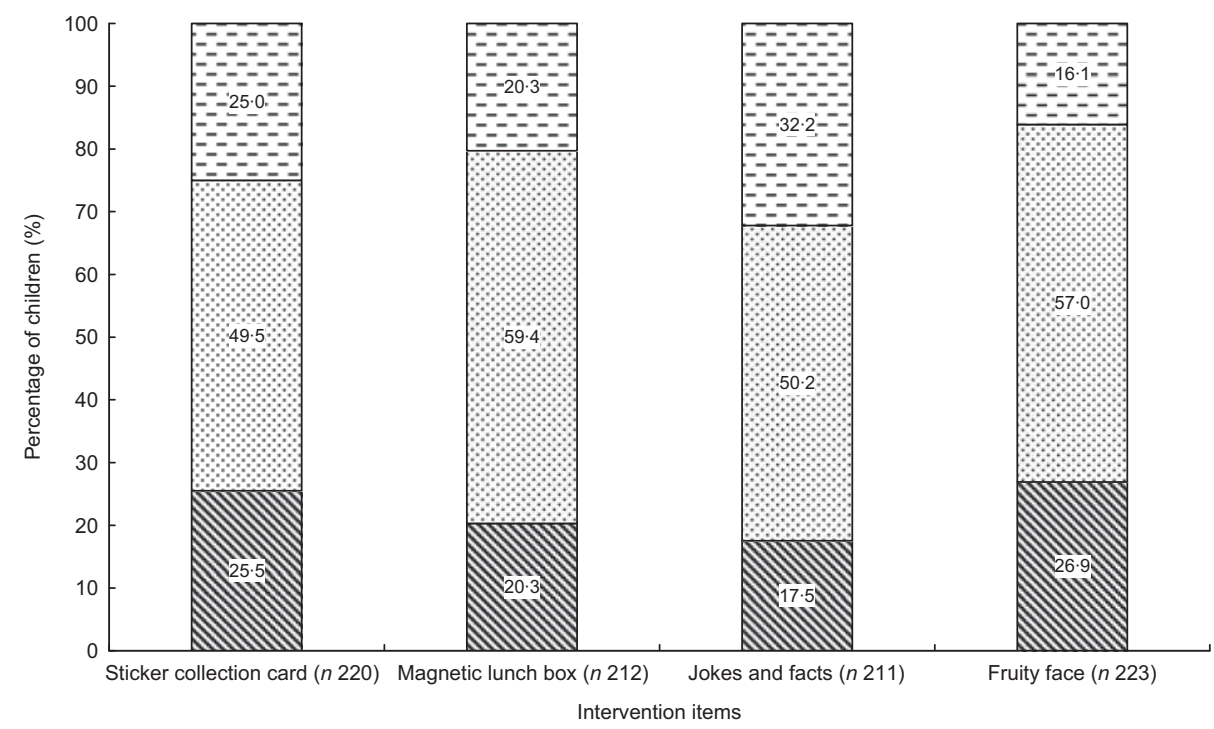

Fig. 3 Intervention items for children. Percentage never using, using and still using intervention items at next phase (E-, never used;

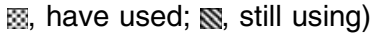

used the individual food boxes whether or not they liked them, so it is not possible to test for significance for this item. These results are presented in Table 4.

The magnetic lunch box and the help leaflet were significantly more likely to be used by girls than boys (Table 4). Gender did not influence whether an item was used or not for all other items. Girls were more likely to like the magnetic lunch box, cloth shopping bag and the lunch-munch chart than boys (Table 5).

\%FSME did not influence how much an item was used for any items except the lunch-munch chart, which was more likely to be used by those children in schools with a high \%FSME. Children in schools with a higher \%FSME were more likely to like the sticker collection card and the jokes and facts.

\section{Discussion}

The intervention items were well liked and used. The individual food boxes, provided to store sandwiches, vegetables and fruit, were the most commonly used item followed by the cooler bag, the fruity face and the water bottle. The least popular items were the lunch-munch chart, the cloth shopping bag and the jokes and facts. Despite their lack of popularity, approximately half of the responding participants still used these items.

Items were more likely to be used if they were well liked for all items except the cooler bag, lunch box and fruity face. These items were practical tools that facilitated children taking a healthy packed lunch to school. It appears items that do not fill a practical function need to 
Table $4 \mathrm{OR}$ and $95 \% \mathrm{Cl}$ of children using an intervention item by gender, \%FSME and liking of the item

\begin{tabular}{|c|c|c|c|c|c|c|c|c|c|}
\hline \multirow[b]{2}{*}{ Intervention item } & \multirow[b]{2}{*}{$n$} & \multicolumn{2}{|c|}{ Percentage used } & \multicolumn{2}{|c|}{ Using item by gender } & \multicolumn{2}{|c|}{ Using item by \%FSME } & \multicolumn{2}{|c|}{ Using item if it was liked } \\
\hline & & OR & $95 \% \mathrm{Cl}$ & OR & $95 \% \mathrm{Cl}$ & OR & $95 \% \mathrm{Cl}$ & OR & $95 \% \mathrm{Cl}$ \\
\hline Individual food boxes & 224 & $98 \cdot 5$ & $94 \cdot 2,99 \cdot 6$ & & * & & * & & * \\
\hline Cooler bag & 225 & $97 \cdot 1$ & $93 \cdot 2,98 \cdot 8$ & $1 \cdot 3$ & $0.2,9.9$ & $0 \cdot 3$ & $0 \cdot 0,3 \cdot 0$ & $6 \cdot 1$ & $0 \cdot 8,47 \cdot 0$ \\
\hline Week-one menus & 220 & $64 \cdot 1$ & $55 \cdot 7,71 \cdot 8$ & $1 \cdot 2$ & $0.6,2 \cdot 5$ & $2 \cdot 0$ & $0.9,4 \cdot 4$ & $2 \cdot 9$ & $1 \cdot 2,7 \cdot 3$ \\
\hline Blank shopping lists & 225 & $73 \cdot 1$ & $65 \cdot 7,79 \cdot 4$ & $1 \cdot 2$ & $0.8,1.9$ & $1 \cdot 0$ & $0 \cdot 6,1 \cdot 4$ & $2 \cdot 1$ & $1 \cdot 3,3 \cdot 3$ \\
\hline Magnetic lunch box & 187 & 63.9 & $56 \cdot 1,71 \cdot 0$ & $5 \cdot \overline{5}$ & $2 \cdot 0,15 \cdot 0$ & $0 \cdot 6$ & $0.2,1.6$ & $20 \cdot 0$ & $6 \cdot 2,63 \cdot 8$ \\
\hline Magnetic memo-board & 180 & $66 \cdot 0$ & $56 \cdot 9,74 \cdot 1$ & $2 \cdot 9$ & $0 \cdot 8,10 \cdot 3$ & $0 \cdot 8$ & $0 \cdot 2,3 \cdot 1$ & $76 \cdot 2$ & $19 \cdot 9,291 \cdot 8$ \\
\hline Wall chart & 222 & $65 \cdot 8$ & $59 \cdot 3,71 \cdot 7$ & $1 \cdot 4$ & $0 \cdot 7,2 \cdot 9$ & $1 \cdot 7$ & $0.8,3.6$ & $2 \cdot 6$ & $1 \cdot 2,5 \cdot 8$ \\
\hline Help leaflet & 184 & $75 \cdot 0$ & $66 \cdot 8,81 \cdot 7$ & $3 \cdot 5$ & $1 \cdot 4,8 \cdot 8$ & $0 \cdot 8$ & $0 \cdot 3,2 \cdot 0$ & $13 \cdot 7$ & $5 \cdot 2,36 \cdot 4$ \\
\hline Cloth shopping bag & 175 & $50 \cdot 5$ & $41 \cdot 8,59 \cdot 2$ & 1.9 & $0 \cdot 8,4 \cdot 3$ & $1 \cdot 2$ & $0.5,2.9$ & $14 \cdot 2$ & $5 \cdot 6,35 \cdot 7$ \\
\hline Fruity face & 223 & $83 \cdot 6$ & $76 \cdot 9,88 \cdot 6$ & $1 \cdot 2$ & $0.5,3.0$ & 0.7 & $0 \cdot 3,2 \cdot 1$ & $2 \cdot 5$ & $0 \cdot 8,7 \cdot 7$ \\
\hline Top grub game & 172 & $76 \cdot 6$ & $66 \cdot 9,84 \cdot 2$ & $1 \cdot 1$ & $0 \cdot 4,3 \cdot 2$ & $3 \cdot 3$ & $0 \cdot 8,13 \cdot 3$ & $42 \cdot 0$ & $10 \cdot 5,168 \cdot 6$ \\
\hline Water bottle & 173 & $80 \cdot 1$ & $70 \cdot 0,87 \cdot 5$ & 1.5 & $0 \cdot 4,5 \cdot 0$ & $0 \cdot 4$ & $0 \cdot 1,1 \cdot 9$ & $32 \cdot 9$ & $8 \cdot 6,125 \cdot 1$ \\
\hline Sticker collection card & 220 & $75 \cdot 2$ & $66 \cdot 6,82 \cdot 1$ & $1 \cdot 2$ & $0 \cdot 5,2 \cdot 8$ & $1 \cdot 1$ & $0 \cdot 4,3 \cdot 2$ & $9 \cdot 3$ & $3 \cdot 4,25 \cdot 4$ \\
\hline Jokes and facts & 176 & $62 \cdot 2$ & $54 \cdot 1,69 \cdot 7$ & $2 \cdot 1$ & $0 \cdot 8,5 \cdot 7$ & $2 \cdot 6$ & $0.8,8 \cdot 4$ & $20 \cdot 7$ & $6 \cdot 8,63 \cdot 4$ \\
\hline Lunch-munch chart & 168 & $46 \cdot 4$ & $39 \cdot 0,54 \cdot 0$ & $1 \cdot 0$ & $0.4,2.5$ & $2 \cdot 5$ & $1 \cdot 0,6 \cdot 2$ & $17 \cdot 7$ & $6 \cdot 5,48 \cdot 2$ \\
\hline
\end{tabular}

\%FSME, percentage free-school-meals eligibility.

${ }^{*}$ OR could not be calculated as $100 \%$ used this item within the subgroups.

Table $5 \mathrm{OR}$ and $95 \% \mathrm{Cl}$ of children liking an intervention item by gender and \%FSME

\begin{tabular}{|c|c|c|c|c|c|c|c|}
\hline \multirow[b]{2}{*}{ Intervention item } & \multirow[b]{2}{*}{$n$} & \multicolumn{2}{|c|}{ Percentage liked } & \multicolumn{2}{|c|}{ Liking item by gender } & \multicolumn{2}{|c|}{ Liking item by \%FSME } \\
\hline & & OR & $95 \% \mathrm{Cl}$ & OR & $95 \% \mathrm{Cl}$ & OR & $95 \% \mathrm{Cl}$ \\
\hline Individual food boxes & 222 & $93 \cdot 2$ & $89 \cdot 1,95 \cdot 9$ & 0.7 & $0 \cdot 2,2 \cdot 0$ & $1 \cdot 4$ & $0.5,4 \cdot 2$ \\
\hline Cooler bag & 223 & $85 \cdot 6$ & $76 \cdot 4,91 \cdot 6$ & 0.9 & $0 \cdot 4,2 \cdot 1$ & $0 \cdot 7$ & $0 \cdot 2,2 \cdot 5$ \\
\hline Week-one menus & 219 & $84 \cdot 3$ & $77 \cdot 6,89 \cdot 3$ & $1 \cdot 0$ & $0 \cdot 5,2 \cdot 2$ & $1 \cdot 4$ & $0 \cdot 6,3 \cdot 3$ \\
\hline Blank shopping lists & 221 & $83 \cdot 6$ & $77 \cdot 7,88 \cdot 3$ & $1 \cdot 5$ & $0 \cdot 7,3 \cdot 2$ & $1 \cdot 4$ & $0 \cdot 6,3 \cdot 0$ \\
\hline Magnetic lunch box & 190 & $84 \cdot 1$ & $76 \cdot 7,89 \cdot 4$ & $4 \cdot 0$ & $1 \cdot 7,9 \cdot 4$ & $1 \cdot 0$ & $0 \cdot 4,2 \cdot 6$ \\
\hline Magnetic memo-board & 186 & $82 \cdot 3$ & $75 \cdot 0,87 \cdot 8$ & 1.9 & $0 \cdot 9,4 \cdot 2$ & 0.9 & $0 \cdot 4,2 \cdot 0$ \\
\hline Wall chart & 219 & $78 \cdot 3$ & $71 \cdot 4,83 \cdot 9$ & $1 \cdot 0$ & $0 \cdot 5,2 \cdot 0$ & $1 \cdot 1$ & $0 \cdot 5,2 \cdot 4$ \\
\hline Help leaflet & 195 & $69 \cdot 5$ & $60 \cdot 7,77 \cdot 2$ & $1 \cdot 2$ & $0 \cdot 6,2 \cdot 3$ & $1 \cdot 3$ & $0 \cdot 6,2 \cdot 8$ \\
\hline Cloth shopping bag & 184 & $67 \cdot 9$ & $60 \cdot 9,74 \cdot 3$ & $1 \cdot 8$ & $1 \cdot 0,3 \cdot 5$ & $0 \cdot 8$ & $0 \cdot 4,1 \cdot 6$ \\
\hline Fruity face & 223 & $89 \cdot 7$ & $85 \cdot 0,93 \cdot 0$ & 0.9 & $0 \cdot 4,2 \cdot 3$ & 1.9 & $0 \cdot 8,4 \cdot 6$ \\
\hline Top grub game & 193 & $88 \cdot 3$ & $81 \cdot 6,92 \cdot 8$ & 0.9 & $0 \cdot 8,5 \cdot 1$ & $2 \cdot 0$ & $0 \cdot 6,6 \cdot 9$ \\
\hline Water bottle & 190 & $85 \cdot 4$ & $78 \cdot 8,90 \cdot 2$ & $2 \cdot 1$ & $0 \cdot 8,5 \cdot 1$ & $2 \cdot 0$ & $0 \cdot 6,6 \cdot 9$ \\
\hline Sticker collection card & 223 & $82 \cdot 5$ & $76 \cdot 4,87 \cdot 2$ & 0.7 & $0 \cdot 3,1 \cdot 7$ & $4 \cdot 7$ & $1 \cdot 3,16 \cdot 4$ \\
\hline Jokes and facts & 186 & $82 \cdot 5$ & $74 \cdot 7,88 \cdot 3$ & $1 \cdot 1$ & $0 \cdot 6,2 \cdot 3$ & $2 \cdot 1$ & $1 \cdot 0,4 \cdot 5$ \\
\hline Lunch-munch chart & 185 & $64 \cdot 3$ & $57 \cdot 2,70 \cdot 9$ & $2 \cdot 1$ & $1 \cdot 1,4 \cdot 0$ & $1 \cdot 2$ & $0 \cdot 6,2 \cdot 4$ \\
\hline
\end{tabular}

\%FSME, percentage free-school-meals eligibility.

be well liked to be used and to have the potential to be effective, but more practical items are less influenced by likeability. The magnetic lunch box and the help leaflet were more likely to be used, and the magnetic lunch box, cloth shopping bag and lunch-munch chart were more likely to be liked by girls than boys. The sticker collection card and the jokes and facts were more likely to be liked in schools with higher \%FSME. These findings support the case for items to be piloted in the target population.

The individual food boxes and cooler bag were more likely to be used compared to all the other items, including the more traditional educational items such as the help leaflet or wall chart. A number of previous interventions relied on educational materials to improve children's diets, many of these were shown to improve knowledge ${ }^{(25)}$ and attitudes ${ }^{(32)}$ but not consumption of healthy foods ${ }^{(33)}$. Wardle and colleagues ${ }^{(34)}$ found that providing educational information did not increase the liking or consumption of a target vegetable. Some of the successful school-based interventions did not rely on educational material but included interactive techniques, such as games, cartoons, rewards and tastings ${ }^{(17,21,35)}$. Simply providing information on what to include in a healthy lunch box is unlikely to have a lasting impact. Such information is currently widely available and the evidence suggests parents need greater practical support and guidance to prepare healthy lunches, just as children need greater encouragement and incentives to consume healthy lunches, than is provided in traditional public health interventions.

The items from the first two phases that were most likely to still be used at the next phase were the plastic boxes, cooler bags and the blank shopping lists. All these items were aimed at parents whereas the items aimed at 
children, e.g. the sticker collection card and fruity faces, were less likely to still be used at the next phase. Intervention items for children may need to be updated regularly to keep children interested, while practical tools that parents can use to prepare healthy lunch boxes may be expected to be used longer. Interactive intervention items may be the most effective option for engaging children. Techniques such as cartoons, adventure games and classroom activities have been shown to be effective in increasing fruit and vegetable consumption ${ }^{(17,21)}$ and decreasing fizzy drink consumption ${ }^{(35)}$.

The effectiveness of the intervention items has not been discussed in the present paper and will be published separately ${ }^{(36)}$. However, the acceptability of intervention items and how this relates to the degree to which items were used has been investigated. The present paper provides a detailed description of the intervention items used, which allows public health professionals to understand and potentially replicate this intervention, which may prove useful in improving public health interventions and future research.

The low number of participants giving feedback on intervention items is a limitation of this analysis, and the variable number of responders to each phase is responsible for the variation in usage results seen in the figures and tables. As we were measuring whether participants said they liked items and used items without checking whether the items were in fact used, the results presented in the paper may be subject to response bias. Additionally, the participants were given the intervention items and it is uncertain whether results would differ if items were purchased. Despite these limitations, a number of useful themes have been identified. These results suggest that providing practical tools to parents is a popular and therefore potentially useful technique for helping parents prepare healthy packed lunches. Items not fulfilling a practical function need to be liked to be used by parents and children and should be tested in the target population to assess acceptability before being introduced.

\section{Conclusion}

Participants are generally more likely to use intervention items if they like them; it is therefore important to pilot intervention items to assess acceptability. Practical intervention items aimed at parents were more likely to be used and to continue to be used in the longer term. Functional tools designed to help parents prepare and children take healthy lunches to school have the potential to improve the foods children consume at school.

\section{Acknowledgements}

The project was commissioned by the Food Standards Agency (reference number N14R0004). The authorship responsibilities are as follows: C.L.C. was involved in designing the intervention and developing materials, and analysing the feedback data. C.E.L.E. was involved in designing and developing materials, coordinating the day-to-day management of the project and analysing the feedback data. M.S.K. was involved in designing and developing materials. J.E.C. was the principal investigator. We would like to thank all the pupils and their parents who took part in this project and provided feedback on the intervention items, the school coordinators and the schools for agreeing to take part in this study. We would also like to thank J Thomas for designing the database and Naked Eye, Faraday Packaging and Design Futures for their help with the design of the intervention materials. We have no conflict of interests to declare.

\section{References}

1. Jotangia D, Moody A, Stamatakis E \& Wardle H (2006) Obesity among children under 11. http://www.dh.gov.uk/prod_ consum_dh/groups/dh_digitalassets/@dh/@en/documents/ digitalasset/dh_065358.pdf (accessed August 2009).

2. Must A \& Strauss RS (1999) Risks and consequences of childhood and adolescent obesity. Int J Obes Relat Metab Disord 23, Suppl. 2, S2-11.

3. Gunnell DJ, Frankel SJ, Nanchahal K, Peters TJ \& Davy Smith G (1998) Childhood obesity and adult cardiovascular mortality: a 57-y follow-up study based on the Boyd Orr cohort. Am J Clin Nutr 67, 1111-1118.

4. Hoffmans MD, Kromhout D \& de Lezenne CC (1988) The impact of body mass index of 78,612 18-year old Dutch men on 32-year mortality from all causes. J Clin Epidemiol 41, 749-756.

5. Must A, Jacques PF, Dallal GE, Bajema CJ \& Dietz WH (1992) Long-term morbidity and mortality of overweight adolescents. A follow-up of the Harvard Growth Study of 1922 to 1935. N Engl J Med 327, 1350-1355.

6. Cross-Government Obesity Unit (2008) Healthy Weight, Healthy Lives: A Cross Government Strategy for England. London: Department of Health and Department of Children, Schools and Families.

7. School Food Trust (2007) A guide to the Government's new food-based standards for school lunches. http:// www.schoolfoodtrust.org.uk/UploadDocs/Library/Documents/ School-food-trust.pdf (accessed August 2009).

8. Gregory J, Lowe S \& Bates CJ (2000) National Diet and Nutrition Survey: Young People Aged 4 to 18 Years. vol. 1: Report of the Diet and Nutrition Survey. London: The Stationery Office.

9. Mintel Group: London (2006) Children's Packed Lunches UK. http://academic.mintel.com/sinatra/oxygen_academic/search_ results/show\&/display/id=173840 (accessed August 2009).

10. Jefferson A \& Cowbrough K (2004) School lunch box survey 2004. http://www.food.gov.uk/multimedia/pdfs/lunchbox2004 report.pdf (accessed August 2009).

11. Evans CEL, Greenwood DC, Thomas JD \& Cade JE (2009) A cross-sectional survey of children's packed lunches in the UK: food and nutrient based results. J Epidemiol Community Health (In the Press).

12. Rees G, Richards CJ \& Gregory J (2008) Food and nutrient intakes of primary school children: a comparison of school meals and packed lunches. J Hum Nutr Diet 21, $420-427$.

13. Rogers IS, Ness AR, Hebditch K, Jones LR \& Emmett PM (2007) Quality of food eaten in English primary schools: 
school dinners vs packed lunches. Eur J Clin Nutr 61, 856-864.

14. School Food Trust (2007) Children's lunchtime choices following the introduction of food-based standards for school lunch; observations from six primary schools in Sheffield. http://www.schoolfoodtrust.org.uk/UploadDocs/Contents/ Documents/childrens_lunchtime_choices.pdf (accessed August 2009).

15. Barton R (2007) The effect of nutrition intervention, using the Balance of Good Health Model, on the composition of the packed lunches of 10-11-year-old schoolchildren. J Hum Nutr Diet 13, 368.

16. Auld GW, Romaniello C, Heimendinger J, Hambidge C \& Hambidge M (1999) Outcomes from a school-based nutrition education program alternating special resource teachers and classroom teachers. J Sch Health 69, 403-408.

17. Baranowski T, Baranowski J, Cullen KW, Marsh T, Islam N, Zakeri I, Honess-Morreale L \& de Moor C (2003) Squire's Quest! Dietary outcome evaluation of a multimedia game. Am J Prev Med 24, 52-61.

18. Baranowski T, Davis M, Resnicow K, Baranowski J, Doyle C, Lin LS, Smith M \& Wang DT (2000) Gimme 5 fruit, juice, and vegetables for fun and health: outcome evaluation. Health Educ Behav 27, 96-111.

19. Friel S, Kelleher C, Campbell P \& Nolan G (1999) Evaluation of the Nutrition Education at Primary School (NEAPS) programme. Public Health Nutr 2, 549-555.

20. Gortmaker SL, Cheung LW, Peterson KE et al. (1999) Impact of a school-based interdisciplinary intervention on diet and physical activity among urban primary school children: eat well and keep moving. Arch Pediatr Adolesc Med 153, 975-983.

21. Lowe CF, Horne PJ, Tapper K, Bowdery M \& Egerton C (2004) Effects of a peer modelling and rewards-based intervention to increase fruit and vegetable consumption in children. Eur J Clin Nutr 58, 510-522.

22. Luepker RV, Perry CL, McKinlay SM, Nader PR, Parcel GS, Stone EJ, Webber LS, Elder JP, Feldman HA \& Johnson CC (1996) Outcomes of a field trial to improve children's dietary patterns and physical activity. The Child and Adolescent Trial for Cardiovascular Health (CATCH) collaborative group. JAMA 275, 768-776.

23. Reynolds KD, Franklin FA, Binkley D, Raczynski JM, Harrington KF, Kirk KA \& Person S (2000) Increasing the fruit and vegetable consumption of fourth-graders: results from the high 5 project. Prev Med 30, 309-319.

24. Sahota P, Rudolf MC, Dixey R, Hill AJ, Barth JH \& Cade J (2001) Randomised controlled trial of primary school based intervention to reduce risk factors for obesity. BMJ $\mathbf{3 2 3}$, 1029-1032.
25. Saksvig BI, Gittelsohn J, Harris SB, Hanley AJ, Valente TW \& Zinman B (2005) A pilot school-based healthy eating and physical activity intervention improves diet, food knowledge, and self-efficacy for native Canadian children. $J$ Nutr 135, 2392-2398.

26. Stone EJ, Osganian SK, McKinlay SM, Wu MC, Webber LS, Luepker RV, Perry CL, Parcel GS \& Elder JP (1996) Operational design and quality control in the CATCH multicenter Trial. Prev Med 25, 384-399.

27. Vandongen R, Jenner DA, Thompson C, Taggart AC, Spickett EE, Burke V, Beilin LJ, Milligan RA \& Dunbar DL (1995) A controlled evaluation of a fitness and nutrition intervention program on cardiovascular health in 10- to 12year-old children. Prev Med 24, 9-22.

28. Walter HJ \& Wynder EL (1989) The development, implementation, evaluation, and future directions of a chronic disease prevention program for children: the 'Know Your Body' studies. Prev Med 18, 59-71.

29. Epstein LH, Gordy CC, Raynor HA, Beddome M, Kilanowski CK \& Paulch R (2001) Increasing fruit and vegetable intake and decreasing fat and sugar intake in families at risk for childhood obesity. Obes Res 9, 171-178.

30. Hopper CA, Munoz KD, Gruber MB, MacConnie S, Schonfeldt B \& Shunk T (2007) A school-based cardiovascular exercise and nutrition program with parent participation: an evaluation study. Child Health Care 25, 221-235.

31. Golan M, Fainaru M \& Weizman A (1998) Role of behaviour modification in the treatment of childhood obesity with the parents as the exclusive agents of change. Int J Obes Relat Metab Disord 22, 1217-1224.

32. Graves K, Shannon B, Sims L \& Johnson S (1982) Nutrition knowledge and attitudes of elementary school students after receiving nutrition education. J Am Diet Assoc 81, 422-427.

33. Shannon B, Graves K \& Hart M (1982) Food behavior of elementary school students after receiving nutrition education. J Am Diet Assoc 81, 428-434.

34. Wardle J, Herrera ML, Cooke L \& Gibson EL (2003) Modifying children's food preferences: the effects of exposure and reward on acceptance of an unfamiliar vegetable. Eur J Clin Nutr 57, 341-348.

35. James J, Thomas P, Cavan D \& Kerr D (2004) Preventing childhood obesity by reducing consumption of carbonated drinks: cluster randomised controlled trial. BMJ 328, 1237.

36. Evans CEL, Greenwood DC, Thomas JD, Cleghorn CL, Kitchen MS \& Cade JE (2009) SMART Lunch Box intervention to improve the food and nutrient content of children's packed lunches: UK wide cluster randomised controlled trial. J Epidemiol Community Health (In the Press). 